\title{
Optimal sizing of Battery Energy Storage System for household microgrid
}

\author{
Libin WANG, Chunhui LI, Jiawei WANG, Haibo ZHAO, Zeyuan SHEN
}

Shanxi Electric Power Company Economic and Technology Research Institute of State Grid,

Taiyuan, Shanxi, 030002,China

email:pwgd2013@163.com

Keywords: Battery Energy Storage System; Microgrid; Load Peak Shaving

\begin{abstract}
Aiming at the peak shaving and poor power quality issues resulted from the intermittent power sources, battery energy storage system (BESS) is generally a key distributed generation unit in microgrid. Therefore this paper presents a sizing optimization method for battery energy storage system in the typical household microgrid based on solar PV and BESS. The mathematic models and the optimization solution algorithm are proposed respectively as to achieve the optimization goal of maximum economic benefit of BESS. The purpose of the proposed method here is to make full use of BESS to improve the system load peak shaving and power quality, as well as take the maximum advantage of the renewable energy resources available.
\end{abstract}

\section{Introduction}

Renewable energy sources are an effective alternative schemes for traditional petrochemical energy as to improve energy saving and environmental protection [1]. In supports of China's renewable energy sources development policy, household microgrid based on distributed generation sources (DG) is becoming one of the solutions to this energy concern recently, which is gaining more and more attention for improving the power reliability, reducing the carbon emissions and cost of electric power. Aiming at the intermittent output features of solar photovoltaic (PV) array and wind turbine generator (WT), battery energy storage system (BESS) is the key factor for sustainable energy to realize flexible control and optimal operation of household microgrid, due to its rapid power adjustment capacity as well as the characteristic of supply and storage capability [2].

Recently design and optimization of BESS have been of recent considerable attention in the literatures [3-11]. Reference [6] introduces various energy storage technologies and their features such as battery energy storage system. Reference [7] builds a chance constrained programming model for the battery size optimization problem based on the analysis of the key factors for battery capacity and the probability model of wind, solar energy and load stochastic characteristics. Similarly, Reference [8] gives a novel method to optimize the hybrid energy storage capacity based on the chance constrained programming, which adopts genetic algorithm (GA) to get the trade-off solution between the minimum cost goal of energy storage and the confidence level of wind power fluctuation. Reference [9] proposes an optimal sizing method to determine the battery size and the corresponding configures of WT and PV unit, which can achieve the customers required loss of power supply probability with a minimum annualized cost of system with genetic algorithm. Reference [10] gives an energy storage sizing optimization approach which considers the convergence speed of the stability region and the state trajectory. In addition, considering the effect of the battery control strategy on the sizing optimization, Reference [11] presents a method to reduce the battery capacity by adopting neural network to control the charging and discharging process of the energy storage device. In conclusion, the methods mentioned as above are all given from its individual different research view points such as the optimization algorithm, the battery control strategy or the minimum cost optimization objective. However, those optimization mathematic models are simple and incomplete not to determine the optimum sizing of battery energy storage system. 
This paper presents a sizing optimization method for battery energy storage system in the typical PV-BESS household microgrid, which is usually installed on the roof of building as to make full use of the green solar renewable energy. Its typical system configuration diagram is shown in Fig.1, where the load can get the power supply from the grid through the power flow controller (PFC). The mathematic model is given to optimize the battery size as to maximize the power economic benefit of BESS, subjected to various equality and inequality constraints. The proposed optimization solution algorithm is built with the operation strategy and constraints of BESS, which can make full use of solar PV renewable energy source available and improve the system load peak shaving.

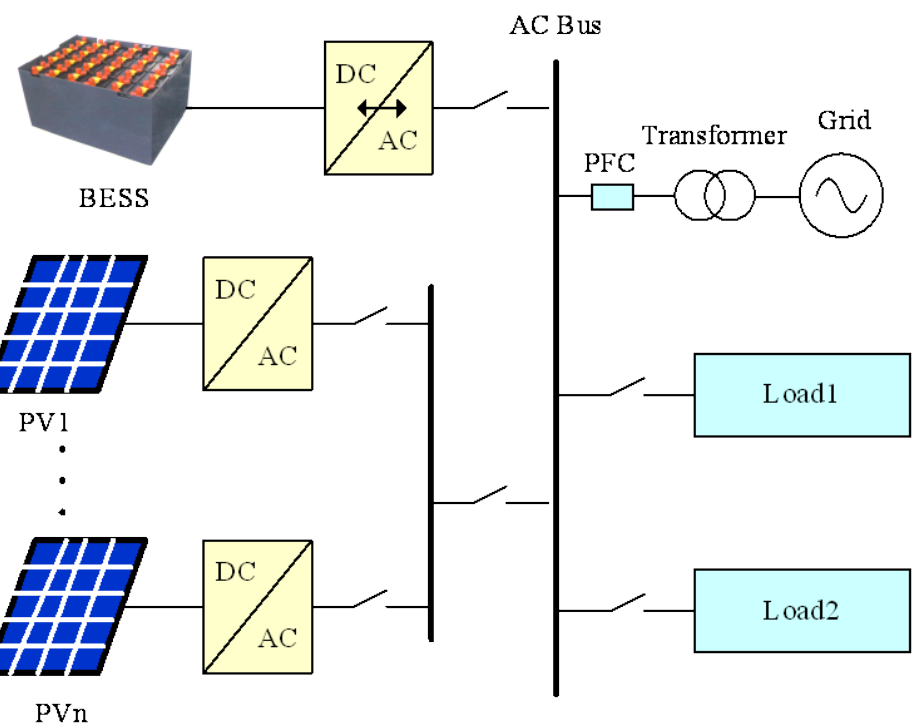

Fig.1. Structure diagram of PV-BESS household microgrid

\section{Problem Formulation}

The battery sizing optimization problem is formulated to gain a maximum economic benefit by allocating the optimum capacity and output power rating of BESS, subjected to a set of equality and inequality constraints according to the characteristics of BESS and microgrid. Thus, the optimization objective of BESS is to maximize the total economic profit which is equal to the electricity power revenue minus its generation cost, based on its key function of load peak shaving.

$$
\text { max profit } f(x)=\sum_{j=0}^{T}\left[\operatorname{Saving}\left(\operatorname{Sizing}_{\text {BESS }}\right)-\operatorname{Cost}\left(\text { Sizing }_{\text {BESS }}\right)\right]
$$

Where, $T$ denotes the planned operation period; Saving $\left(\right.$ Sizing $\left._{B E S S}\right)$ is the unit economic profit function which depends on the system net-load peak shaving power demand quantity within the planned operation period of BESS; Cost(Sizing $\left.{ }_{B E S S}\right)$ is the unit costs per power of BESS.

Thus, the economic saving function (Saving $\left(\right.$ Sizing $\left._{B E S S}\right)$ ) for BESS peak shaving is expressed in Eq.(2).

$$
\text { Saving }\left(\text { Sizing }_{B E S S}\right)=\sum_{j=0}^{T}\left(P R_{R E S}+P R_{E S-R E S}\right) \times P_{B E S S}(t)
$$

Where, $P R_{R E S}$ represents the local electricity price of renewable energy source generated from renewable energy source $(¥ / \mathrm{kWh}) ; P R_{E S-R E S}$ is the local electricity price subsidies available for renewable energy source according to the regulatory or legislative policy( $¥ / \mathrm{kWh}) ; \quad P_{B E S S}(t)$ represents the discharging power of BESS $(\mathrm{kW})$ at time interval $t$.

Moreover, the unit cost of BESS ( $\operatorname{Cost}\left(\right.$ Sizing $\left._{B E S S}\right)$ ) is expressed as below.

$$
\begin{gathered}
\operatorname{Cost}\left(\text { Sizing }_{B E S S}\right)=\left(I C_{B E S S}+M C_{B E S S}\right) / T E_{\text {BESS }} \\
I C_{\text {BESS }}=\left(C_{p} P_{B E S S}^{R D}+C_{E} E_{B E S S}^{R D}\right) \times \frac{i(1+i)^{n}}{(1+i)^{n}-1}
\end{gathered}
$$




$$
\begin{aligned}
M C_{B E S S} & =C_{M O} \times T E_{B E S S} \\
T E_{B E S S} & =\sum_{j=0}^{T} P_{B E S S}(t)
\end{aligned}
$$

Where, $I C_{B E S S}$ is the initial investment cost of BESS; $M C_{B E S S}$ is the maintenance and operating (M\&O) cost of BESS; $T E_{B E S S}$ is the estimated total discharged electric energy of BESS, which is usually got from its enterprise; $C_{p}$ is the unit power cost of BESS; $P_{B E S S}^{R D}$ is the rated charge or discharge power of BESS; $C_{E}$ is the unit capacity cost of BESS [12]; $E_{B E S S}^{R D}$ is the rated capacity of BESS; $t$ is the annual interest rate; $n$ is the life span of BESS; $C_{м о}$ is the unit M\&O cost per power of BESS.

In addition, BESS has its special operation and control characteristics such as state of charge (SOC), depth of discharge (DOD), charging-discharging efficiency $(\eta)$ and so on. Therefore, the following constraints should be met for BESS.

$$
\begin{gathered}
P_{B E S S}(t)=P_{\text {load }}(t)-P_{R E S}(t) \\
P_{B E S S}^{\min } \leq P_{B E S S}(t) \leq P_{B E S S}^{\max } \\
S O C_{B E S S}^{\min } \leq S O C(t) \leq S O C_{B E S S}^{\max }
\end{gathered}
$$

According to the mentioned above, the two key decision variables of battery rated power $\left(P_{B E S S}^{R D}\right)$ and rated capacity ( $E_{B E S S}^{R D}$ ) can be formulated by the followings.

$$
\begin{gathered}
P_{B E S S}^{R D}=\max \left[P_{B E S S}\left(t_{1}\right), P_{B E S S}\left(t_{1}\right), \cdots P_{B E S S}\left(t_{N}\right)\right] \\
E_{B E S S}^{R D}=\max E_{B E S S}^{T} / \eta / \alpha
\end{gathered}
$$

Where, $P_{B E S S}\left(t_{j}\right)$ is the real charging-discharging power of BESS at the $j$ th time interval $t ; \alpha$ is the effective energy capacity ratio of BESS; $\max E_{B E S S}^{T}$ is the maximum battery energy capacity available to supply the system load demand during the whole operation period, which is formulated in Eq.(12).

$$
\max E_{B E S S}^{T}=\max \left(\left|\sum_{j=0}^{1} P_{B E S S}(t) \times t\right|,\left|\sum_{j=0}^{2} P_{B E S S}(t) \times t\right|, \cdots,\left|\sum_{j=0}^{T} P_{B E S S}(t) \times t\right|\right)
$$

\section{Sizing Optimization Algorithm}

Genetic algorithm (GA) is a typical population-based heuristic optimization algorithm, which has been applied to a variety of optimization problems [13]. The models mentioned as above are used for developing an algorithm to determine the optimum sizing of BESS, which can gain the maximum economic profit based on its important load peak shaving function. Therefore, a GA is used to assist solving the optimum sizing of BESS for household microgrid, and the BESS sizing optimization process is proposed in Fig.2. The sizing optimization program is divided into three necessary sections of input (database), supporting database (constraints) and output (optimal sizing result). This is a constrained optimization problem with an objective economic profit function to be maximized subject to a set of constraints, thus the details of the simulation algorithm are given as below:

\section{Database}

The essential basic data for the proposed optimization algorithm are collected and stored in a database, which mainly includes as follows.

(1) Hourly demand load profile of the local household;

(2) Hourly solar insolation;

(3) The total power production capacity of solar PV renewable energy generators available;

(4) Unit price of power generated by PV renewable energy unit;

(5) Unit price of local electric power from grid;

(6) The whole time scale for the sizing optimization.

(7) The required power deviation of solar PV unit; 
(8) The maximum depth of discharge (DOD) for battery bank;

(9) The charging-discharging efficiency of BESS.

(10) The setting of GA parameters.

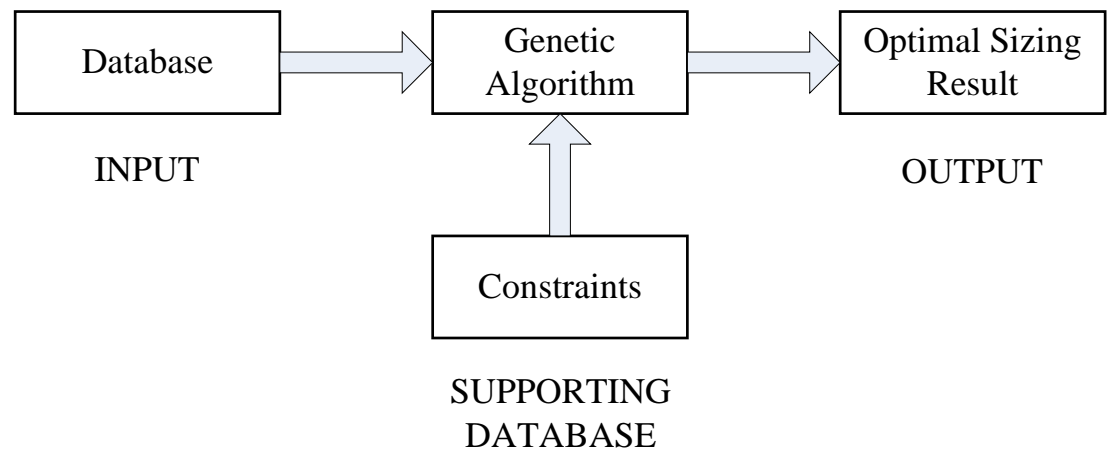

Fig.2. BESS sizing optimization process

\section{Constraints}

The necessary constraints are designed according to the work characteristics of each type of distributed generation units, as well as the safe and stable operation requirements of microgrid. Thus, the constraints could be broadly designed as below.

(1) The electric power generated by PV renewable energy distributed generation should be used as much as possible;

(2) The ramp rate limits of local grid;

(3) The minimum SOC of battery bank;

(4) The maximum SOC of battery bank;

\section{Optimal economic scheduling strategy}

As it is known that the economic scheduling strategy has a critical influence upon the operation performance of microgrid given different sizes and configurations [14]. In another word, the sizing of BESS can differ based on the different economic scheduling strategy. The optimal economic scheduling strategies are summarized and modeled as below.

Battery charging strategy: (i) only to absorb the surplus power that the renewable power exceeds the load demand, until the maximum battery SOC is reached or the renewable power is unable to meet the load demand; (ii) battery cannot charge energy from grid.

Battery discharging strategy: (i) only to assist renewable generation units to meet the load demand prior to the grid, while the renewable power cannot meet the load demand; (ii) BESS can inject the excessive power into the grid for sales when battery bank cannot absorb the future forecasted excessive renewable power.

Renewable energy generation strategy: (i) first priority to produce power as much as possible until the maximum battery SOC is reached; (ii) the renewable power cannot be injected straightly into the grid just the safe and stable operation requirements.

Grid can supply the electric power through power flow controller (PFC) near to the point of common coupling (PCC) when the household load cannot be met by PV and BESS.

\section{Results and Discussion}

The proposed method is applied to a household microgrid in Guangdong province, China, where the collection of a typical yearly (12 months) data of load demand is recorded for each hour, which is piloted in Fig.3. There are two sets of 15kW PV arrays installed on the roof of the house, whose power output is shown in Fig.4. For GA algorithm, the population size is 50, evolutionary generations are 400 , crossover rate is 0.3 , and mutation rate is 0.4 . 


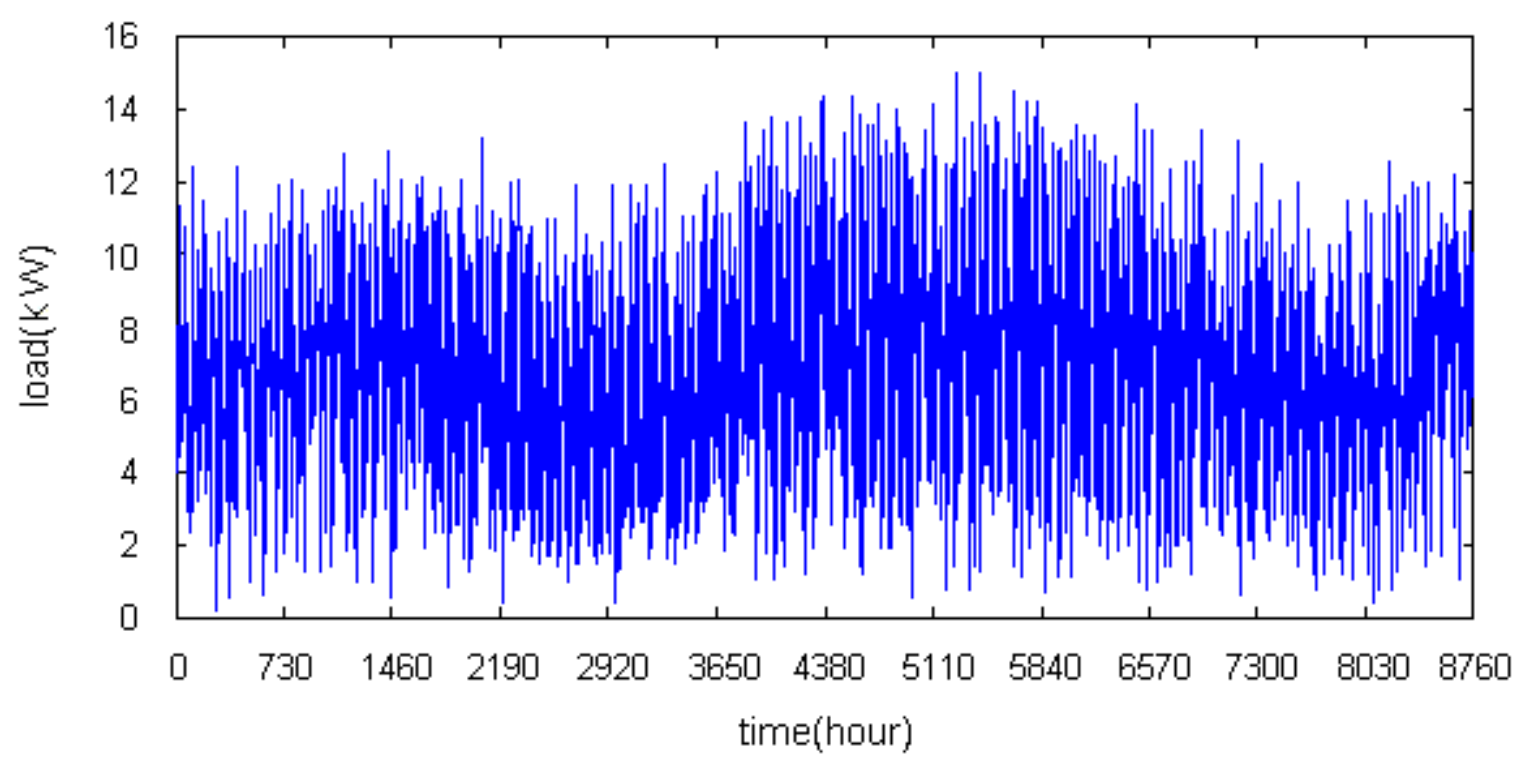

Fig.3. Load demand curve in a typical year

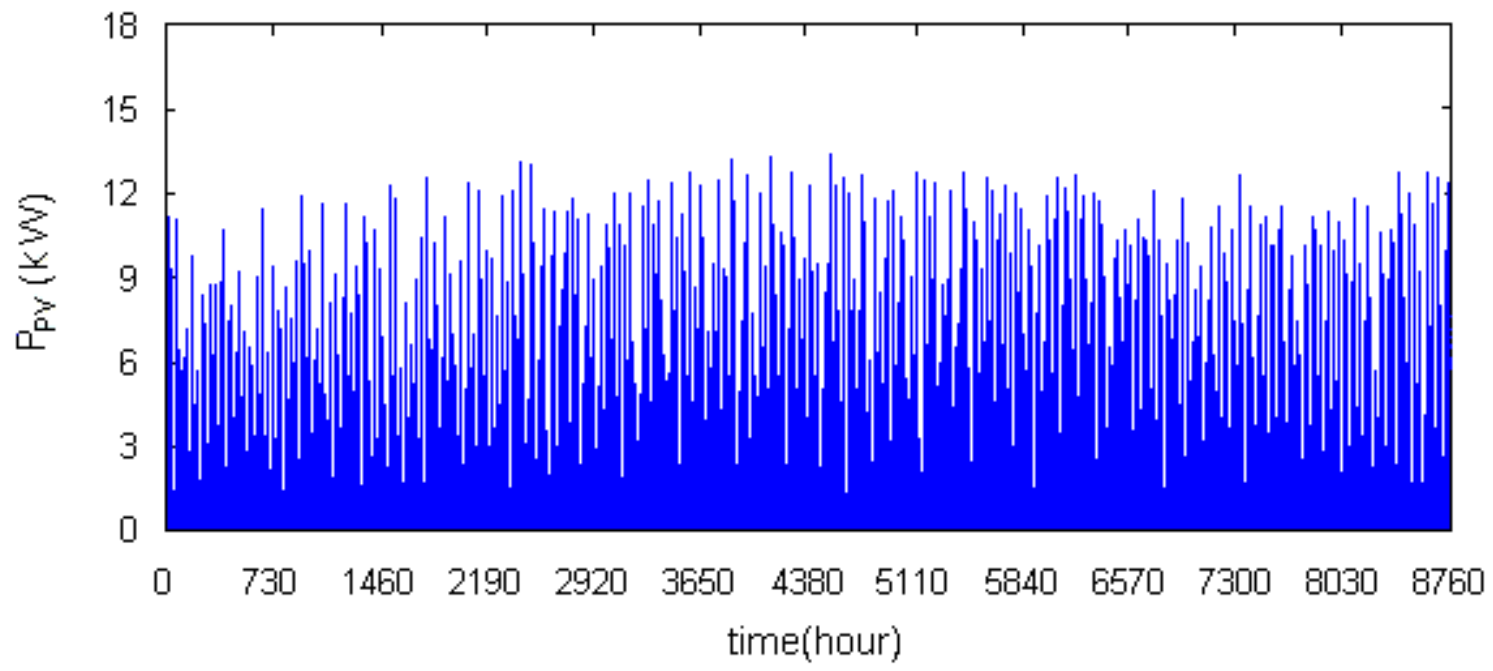

Fig.4. Output power curve of PV in a typical year

Table 1 The basic parameter values of BESS

\begin{tabular}{|c|c|c|}
\hline \multirow{2}{*}{ Parameter } & \multicolumn{2}{|c|}{ Value } \\
\cline { 2 - 3 } & VRLA battery & Lithium-ion battery \\
\hline$S O C_{B E S S}^{\text {min }}$ & 0.3 & 0.2 \\
\hline$S O C_{B E S}^{\text {max }}$ & 0.9 & 0.9 \\
\hline Charge-discharge efficiency $\eta(\%)$ & 80 & 90 \\
\hline$C_{p}(Y \mathrm{~kW})$ & 500 & 1100 \\
\hline$C_{E}(Y / \mathrm{kWh})$ & 600 & 1360 \\
\hline$C_{M O}(¥ / \mathrm{kWh})$ & 0 & 8 \\
\hline$n($ year $)$ & 8 & 10 \\
\hline
\end{tabular}

In order to analyze the influence of the battery types on the sizing solution, two different candidates of valve regulated lead-acid (VRLA) battery and packed modular lithium-ion (PMLI) battery are selected, and their basic parameters are listed in Table 1 . Thus, with the proposed optimization models and the optimization algorithm mentioned as above, the optimum sizing solutions are listed in Table 2, which shows the two decision variables of battery rated power, battery rated capacity and the optimization goal of the maximum economic profit for these two different kinds of batteries. It is known that VRLA battery can gain the more earning profit (RMB25721.0451) than PMLI battery (RMB19401.2682), so the optimum battery type is VRLA 
battery, and the optimal battery sizing solution is: $P_{B E S S}^{R D}=20 \mathrm{~kW}$ and $E_{B E S S}^{R D}=160 \mathrm{kWh}$.

Table 2 Optimal sizing results of BESS

\begin{tabular}{|c|c|c|c|}
\hline Battery type & $P_{B E S S}^{R D}(\mathrm{~kW})$ & $E_{B E S S}^{R D}(\mathrm{kWh})$ & max profit $(¥)$ \\
\hline VRLA battery & 20 & 160 & 25721.0451 \\
\hline PMLI battery & 20 & 120 & 19401.2682 \\
\hline
\end{tabular}

In addition, the required output power rating $\left(P_{\text {BESS }}\right)$ and the rated capacity $\left(E_{B E S S}\right)$ of BESS are closely related to the system net-load peak level (load demand minus output power of PVs). In order to analyze its influence on the battery sizing (the output power and the capacity index), their correlation analysis are piloted in Fig.5. It is obviously to know that the required battery output power and capacity are both increased accordingly when the system net-load peak becomes higher.

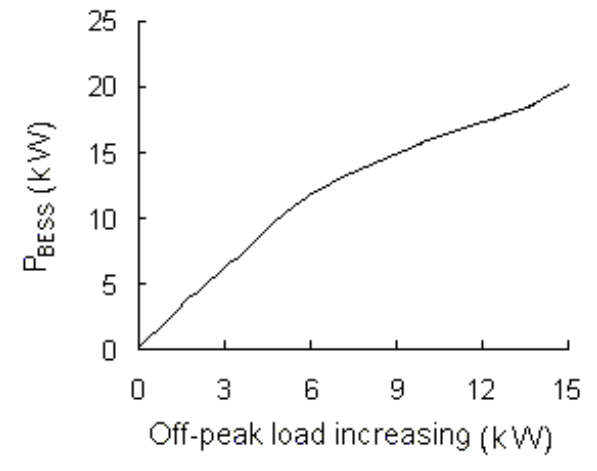

(a) Power demand curve

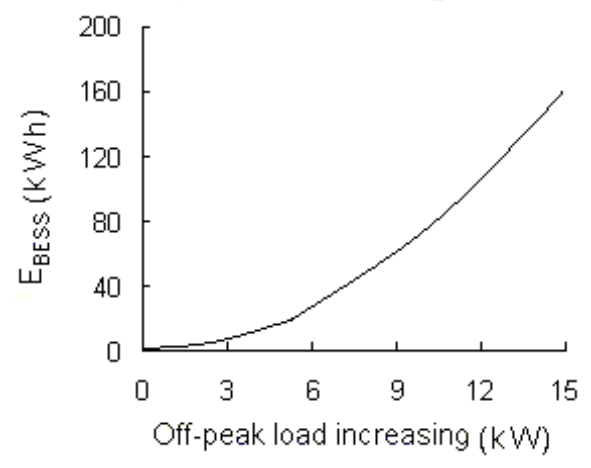

(b) Capacity demand curve

Fig.5. Correlation analysis between load peak and battery sizing

\section{Conclusion}

This paper presented an optimal sizing method of battery energy storage systems for household microgrid, which can determine the optimum the rated power and the rated capacity of battery energy storage system as to achieve the maximum economic profit during its whole life time. The optimization solutions are discussed in a case of household PV-BESS microgrid, which also show the feasible and valuable conclusions: (i) BESS sizing will differ based on the different system net-load peak volume; (ii) the peak shaving function of BESS is very important, but its existing higher cost is still the key bottleneck of BESS large-scale applications.

\section{References}

[1] D. Saheb-Koussa, M. Haddadi, M. Belhamel, Economic and technical study of a hybrid system (wind-photovoltaic-diesel) for rural electrification in Algeria [J]. Apply Energy. 2009 86(7-8) 1024-1030.

[2] Liao Huaiqing, Liu Dong, and Huang Yuhui, A Study on Compatibility of Smart Grid Based on Large-scale Energy Storage System[J]. Automation of Electric Power Systems. 2010 34(2) 15-19.

[3] Yang Ping, Ma Yiwei. Application of energy storage technology in wind power generation [J]. Journal of Systems Science and Mathematical Sciences, 201232 (4) 410-417.

[4] B. Dunn, H. Kamath, J. Tarascon. Electrical energy storage for the grid: a battery of choices [J]. Science, 2011 334(6058) 928-935.

[5] K.C.Divya, Jacob Østergaard. Battery energy storage technology for power systems-An overview [J], Electric Power Systems Research. 200979 511-520.

[6] I. Sharma, K. Bhattacharya. Optimal sizing of battery energy storage systems in unbalanced distribution feeders [C], 39th Annual Conference of the IEEE Industrial Electronics Society, IECON 2013. 2133-2138. 
[7] Sun Yaojie, Kang Longyun, Shi Weixiang, et al. Study on sizing of batteries for distributed power system utilizing chance constrained programming [J]. Journal of System Simulation, 2005 17(1) 41-44.

[8] Xie Shixiao, Yang Li, Li Lina. A chance constrained programming based optimal configuration method of hybrid energy storage system [J]. Power System Technology. 2012 36(5) 79-84.

[9] Yang Hongxing, Zhou Wei, Lu Lin, Fang Zhaohong. Optimal sizing method for stand-alone hybrid solar-wind system with LPSP technology by using genetic algorithm [J]. Solar Energy, 2008 84(4) 354-367.

[10] Wu Yunliang, Sun Yuanzhang, Xu Jian, et al. Determination methodology for energy storage capacity based on saturation control theory [J]. Proceedings of the CSEE. 2011 31(22) 32-38.

[11] C. Abbey, K. Strunz, G. Joos., A knowledge-based approach for control of two-level energy storage for wind energy systems. IEEE Transactions on Energy Conversion. 2009 2(24) 539-547.

[12] Xiu Xiaoqing, Li Jianlin, Hui Dong. Capacity configuration and economic evaluation of energy storage system for grid peak load shifting [J]. Electric Power Construction. 2013 34(2) 1-5.

[13] Goldberg DE. Genetic algorithms in search, optimization and machine learning. New York: Addison-Wesley, 1989.

[14] Xue Meidong, Zhao Bo, Zhang Xuesong, et al. Economic dispatch of stand-alone photovoltaic-battery-hydro-diesel hybrid microgrid based on distributed control [J], 2014 38(4) 1-7. 